\title{
PENGARUH KINERJA KEUANGAN, BIAYA KEAGENAN, DAN TATA KELOLA TERHADAP KEMUNGKINAN FINANCIAL DISTRESS
}

\author{
Aldo Leo Handoko dan Sarwo Edy Handoyo \\ Program Studi Manajemen Bisnis Fakultas Ekonomi, Universitas Tarumanagara, Jakarta \\ Email: leohandokoaldo@gmail.com
}

\begin{abstract}
This research aims to study the effect of financial performance, agency cost, and corporate governance on financial distress likelihood. This research subjects are manufacture firms listed in Indonesian Stock Exchange (BEI) in 2017-2019. This research observing firms annual and financial reports to collect data. Sample selection using purposive sampling, and 117 data used in this research. This research using logistic regression test. This research results are current ratio negatively effecting financial distress likelihood, debt to asset ratio not effecting financial distress likelihood, agency cost not effecting financial distress likelihood, managerial ownership positively effecting financial distress likelihood, institutional ownership not effecting financial distress likelihood, and independent commissioner proportion negatively effecting financial distress likelihood.
\end{abstract}

Keywords: Financial Distress, Financial Performance, Agency Theory, Agency Cost, Corporate Governance.

Abstrak: Penelitian ini bertujuan untuk mengetahui pengaruh kinerja keuangan, biaya keagenan, dan tata kelola perusahaan terhadap kemungkinan financial distress. Subjek penelitian merupakan perusahaan manufaktur yang terdaftar di BEI pada tahun 2017-2019. Penelitian ini mengobservasi pada laporan tahunan dan keuangan. Pemilihan sampel dilakukan dengan purposive sampling, dan jumlah sampel data yang digunakan sebanyak 117. Penelitian ini menggunakan pengujian regresi logistik. Hasil penelitian menunjukkan current ratio berpengaruh negatif terhadap kemungkinan financial distress, debt to asset ratio tidak berpengaruh terhadap kemungkinan financial distress, agency cost tidak berpengaruh terhadap kemungkinan financial distress, managerial ownership berpengaruh positif terhadap kemungkinan financial distress, institutional ownership tidak berpengaruh terhadap kemungkinan financial distress, serta independent commissioner proportion berpengaruh negatif terhadap kemungkinan financial distress.

Kata Kunci: Financial Distress, Kinerja Keuangan, Agency Theory, Agency Cost, Tata Kelola Perusahaan.

\section{LATAR BELAKANG}

Hal terpenting dalam pendirian perusahaan adalah keberlangsungan hidup perusahaan itu sendiri atau going concern. Perusahaan yang bangkrut ini akan merugikan stakeholder perusahaan. Sektor industri manufaktur, yang menjadi pendongkrak PDB Indonesia, dengan kontribusi terhadap PDB sebesar 19,91\%, mengalami perlambatan pertumbuhan dari 5.14\% menjadi 4.68\% untuk tahun 2017 ke 2019 (Katadata, 2020). Data ini mengindikasikan adanya penurunan kinerja pada perusahaan, yang memungkinkan terjadinya kebangkrutan perusahaan. Diperlukan suatu early warning system pada perusahaan agar dapat mencegah risiko kebangkrutan. Kebangkrutan pada perusahaan nantinya akan berdampak pada penurunan perekonomian Indonesia, sehingga perlu diwaspadai dan ditanggulangi agar tidak terjadi.

Penurunan kinerja perusahaan akan berisiko pada kondisi financial distress perusahaan. 
Financial distress merupakan indikasi awal perusahaan sedang dalam kondisi keuangan yang sulit, mengalami kerugian operasional bisnis, penurunan nilai ekuitas, ketidakmampuan

melunasi kewajiban yang telah jatuh tempo beserta dengan biaya modal, atau pengugatan hukum oleh pihak ketiga tidak terbayarnya kewajiban. Financial distress disebabkan oleh masalah likuiditas, solvabilitas, dan tata kelola perusahaan (Lizal, 2002). Tanda perusahaan memiliki masalah dalam manajemen perusahaan yang dapat disebabkan oleh keputusan manajemen yang kurang baik dan atau agency conflict, yang timbul karena agency theory (Jensen \& Meckling, 1976; Scott, 2003).

Tujuan Penelitian ini adalah untuk mengemukakan pengaruh kinerja keuangan, biaya keagenan, dan tata kelola perusahaan terhadap kemungkinan financial distress pada suatu perusahaan. Model penelitian ini telah banyak dilakukan. Namun, penelitian-penelitian terdahulu menunjukkan hasil yang tidak konsisten. Maka dari itu, akan dilakukan penelitian ulang tentang pengaruh kinerja keuangan, biaya keagenan, dan tata kelola perusahaan terhadap kemungkinan financial distress pada perusahaan manufaktur yang terdaftar di BEI tahun 20172019.

\section{KAJIAN TEORI}

Kebangkrutan merupakan ketidakpastian kemampuan perusahaan untuk melanjutkan kegiatan operasional jika kondisi keuangan perusahaan dalam keadaan buruk dan menurun kinerjanya (Lesmana, 2003:174). Sebelum bangkrut, perusahaan akan mengalami kondisi yang disebut financial constraint atau financial distress. Menurut Platt \& Platt (2002), financial distress sebagai kondisi perusahaan mengalami laba bersih operasi negatif, menghentikan pembayaran dividen, dan mengalami restrukturisasi. Sedangkan Dwijayanti (2010) menjelaskan kebangkrutan terbagi menjadi economic distress dan financial distress, dengan economic distress kegagalan menghasilkan pendapatan dan menutupi seluruh biaya perusahaan, dan financial distress kegagalan melunasi kewajiban jatuh tempo dan porsi hutang yang besar.

Agency theory merupakan suatu hubungan kontrak antara shareholder sebagai prinsipal dengan manajemen sebagai agen perusahaan (Jensen \& Meckling, 1976). Agen diminta bekerja menggantikan shareholder dalam kontrol perusahaan, sebab agen yang ditunjuk untuk mengelola perusahaan merupakan para profesional dan ahli yang dapat meningkatkan kekayaan shareholder. Namun, Eisenhardt (1989:59) menjelaskan tiga asumsi dalam teori keagenan, yakni asumsi sifat manusia, asumsi keorganisasian, dan asumsi informasi. Asumsi sifat manusia menjelaskan manusia memiliki sifat self-interest, bounded rationality, dan risk averse. Asumsi keorganisasian menjelaskan dalam perusahaan akan ada konflik kepentingan dan menimbulkan asymmetric information. Sedangkan asumsi informasi menjelaskan bahwa informasi dipandang sebagai komoditas yang berharga dan dapat diperjualbelikan.

Menurut Platt \& Platt (2002), "Financial distress is defined as a late stage of corporate decline that precedes more cataclysmic events such as bankruptcy or liquidation". Menurut Beaver et al. (2010), "Financial distress refers to the inability of a company to pay its financial obligation as the mature". Berdasarkan pendapat tersebut, financial distress merupakan kondisi perusahaan tidak mampu menjalankan usaha, karena perusahaan memiliki kesulitan keuangan yang tampak dari masalah likuiditas yang tidak mampu untuk melunasi hutang jatuh tempo, dan masalah solvabilitas, yang tidak mampu untuk melunasi seluruh hutang yang dimiliki perusahaan walaupun seluruh aset telah dilikuidasi.

Menurut Matar \& Eneizan (2018), "Financial performance is the measure of the financial health of the organization and shows the performance of the executives leadership of the company". Dengan demikian kinerja keuangan merupakan pengukuran dari kinerja perusahaan dalam suatu periode di masa lalu yang menggambarkan kondisi tingkat kesehatan perusahaan, serta penilaian shareholder atas kinerja manajemen perusahaan. 
Rasio likuiditas adalah penilaian kemampuan perusahaan untuk melunasi kewajiban yang akan jatuh tempo (Ahrendsen \& Katchova, 2012). Masalah likuiditas ini menandakan perusahaan berisiko untuk mengalami financial distress (Platt \& Platt, 2002; Beaver et al., 2010). Hal ini mengindikasikan bahwa perusahaan yang likuid cenderung aman dan mampu untuk melunasi kewajiban jatuh temponya.

Rasio solvabilitas adalah rasio yang menilai kemampuan perusahaan untuk melunasi semua hutang jika seluruh asetnya digunakan untuk menutupi hutang perusahaan tersebut (Ahrendsen \& Katchova, 2012). Masalah solvabilitas memungkinkan perusahaan untuk mengalami kondisi financial distress (Platt \& Platt, 2002; Beaver et al., 2010). Hal ini mengindikasikan perusahaan yang memiliki hutang yang besar cenderung kurang sehat dan berisiko financial distress.

Menurut Jensen \& Meckling (1976), "Agency cost definition is as the sum of the monitoring expenditures by the principal, the bonding expenditures by agent, and the residual loss". Monitoring cost adalah pengeluaran untuk mengawasi agen melalui budget restriction dan compensation policies. Bonding cost adalah pengeluaran untuk mematuhi mekanisme penjaminan bahwa agen akan bertindak mementingkan shareholder. Residual losses adalah ketidaksamaan keputusan yang dipilih oleh agen dengan prinsipal. Menurut Brigham \& Daves (2007:11), "To reduce agency conflicts, stockholder must incur agency costs, which include all cost borne by shareholder to encourage managers to maximize the firm's long-term stock price rather than act in their own self-interest". Berdasarkan uraian tersebut, agency cost merupakan biaya-biaya yang dikeluarkan dan ditanggung oleh shareholder untuk mendorong motivasi manajemen untuk bertindak atas kepentingan shareholder, yang timbul karena adanya pemisahan atas kepemilikan dan kontrol perusahaan. Agency cost yang tinggi merupakan tanda terdapat perbedaan kepentingan shareholder dan manajemen.

Agency cost (general \& administrative expense), sebagai pengeluaran sumber daya untuk kepentingan pribadi dan penghasilan tambahan seperti gaji manajerial, pengeluaran eksekutif, dan pengeluaran lain yang ditujukan untuk mengelola perusahaan, yang mana pemborosan sumber daya akan berdampak pada kondisi perusahaan kurang efisien dan berdampak pada risiko financial distress (Li et al., 2008), yang Jensen \& Meckling (1976) sebut perquisite dan Brigham \& Daves (2007) sebut wasteful spending. Agen yang bersifat self-interest (Eisenhardt, 1989), memungkinan terjadinya agency cost yang tinggi, yang akan berdampak pada penurunan firm value shareholder (Jensen \& Meckling, 1976).

Menurut Keputusan Menteri BUMN No. KEP-117/M-MBU/2002, "Corporate governance adalah suatu proses dan struktur yang digunakan oleh organ BUMN untuk meningkatkan keberhasilan usaha dan akuntabilitas perusahaan guna mewujudkan nilai shareholder dalam jangka panjang dengan tetap memperhatikan kepentingan stakeholder lainnya, berlandaskan peraturan perundangan dan nilai-nilai etika”. Menurut Luqman et al. (2018), "Corporate governance is an internal system encompassing policies, processes, and people who serve the needs of shareholder and other stakeholders by directing and controlling management activites with good business practices, objectivity, and integrity. Corporate governance is also a set of mechanisms by which outside investors protect themselves against expropriation by insiders". Dengan demikian tata kelola perusahaan merupakan serangkaian bentuk dan praktik dalam hal mencapai tujuan perusahaan, yaitu meningkatkan nilai perusahaan, menyejahterahkan kepentingan stakeholder perusahaan, serta mengurangi kecurangan internal perusahaan yang dapat merugikan stakeholder. Corporate governance meningkatkan transparansi kinerja perusahaan dan menjadi alat untuk menekan agency cost (Shleifer \& Vishny, 1997).

Managerial ownership merupakan kepemilikan saham oleh anggota direksi dan dewan komisaris (Witiastuti \& Suryandari, 2016; Prastiwi \& Dewi, 2019; Sanny \& Warastuti, 2020). 
managerial ownership sebagai penyelarasan kepentingan manajemen dengan shareholder, yang mana manajemen akan lebih memedulikan aktivitas meningkatkan firm value dibandingkan kepentingan pribadi (Jensen \& Meckling, 1976; Scott, 2003). Managerial ownership juga menjadi mekanisme pengikat kepada manajemen untuk bertindak memaksimalkan firm value dan membagi risiko kepada manajemen akibat kelalaian manajemen sendiri (Ahmad \& Septriani, 2008). Dengan begitu, manajemen akan bersikap lebih berhati-hati dan tidak eksploitatif agar perusahaan tidak mengalami financial distress, disebabkan manajemen juga akan merasakan dampak financial distress tersebut dari penurunan firm value.

Institutional ownership merupakan kepemilikan saham oleh pemerintah, institusi badan hukum, dana perwalian, institusi asing, dan institusi lainnya (Sanny \& Warastuti, 2020). Institutional ownership sebagai mekanisme pengawasan manajemen untuk bertindak atas kepentingan shareholder. Institusi juga memiliki kemampuan yang lebih profesional dalam menilai manajemen dibandingan shareholder individu (Brigham \& Daves, 2007; Ahmad \& Septriani, 2008), dan pengawasannya jauh lebih murah dan efisien (Udin et al., 2017). Institutional ownership dapat memengaruhi tata kelola perusahaan karena kepemilikan perusahaan sangat besar dan memiliki pengendalian yang besar, serta menjadi penggerak harga saham (Brigham \& Daves, 2007; Udin et al., 2017). Dengan institusi selaku shareholder mayoritas dapat mengambil keputusan dalam RUPS, dan memaksa manajemen untuk bertindak atas kepentingan shareholder dengan adanya ancaman, sehingga manajemen akan lebih berhatihati dalam mengelola perusahaan agar tidak mengalami financial distress.

Independent commissioner proportion merupakan jumlah komisaris independen dari keseluruhan dewan komisaris (Witiastuti \& Suryandari, 2016; Nursiva \& Widyaningsih, 2020; Sanny \& Warastuti, 2020). Pengawasan manajemen oleh prinsipal secara langsung sulit dilakukan (Scott, 2003), sehingga prinsipal akan merekrut orang untuk mengawasi manajemen yakni komisaris independen (Luqman et al., 2018). Pengawasan yang mewakili shareholder, dipercaya mampu menjaga perusahaan dari tindakan dan keputusan oportunistik manajemen yang merugikan perusahaan dan menjadikan perusahaan dalam kondisi financial distress. Keberadaan dewan yang independen akan mencegah konflik keagenan (Manzaneque et al., 2016), dan menjauhkan perusahaan dari penurunan firm value.

Kerangka pemikiran dalam penelitian ini digambarkan sebagai berikut:

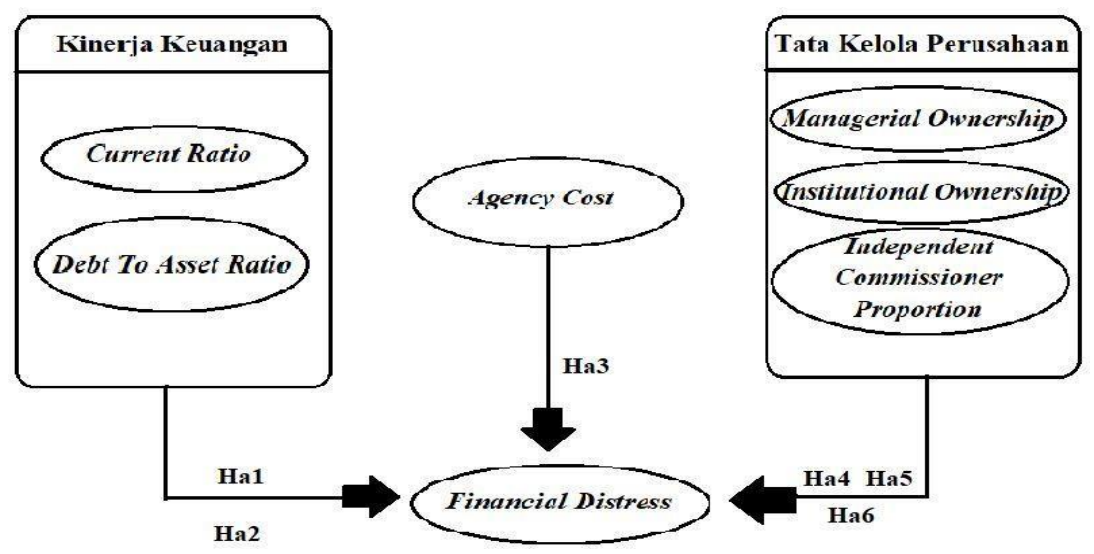

Gambar 1. Kerangka Pemikiran

Hipotesis dari model yang dibangun dari kerangka pemikiran di atas sebagai berikut:

Ha1: Current ratio berpengaruh negatif signifikan terhadap kemungkinan financial distress.

Ha2: Debt to asset ratio berpengaruh positif signifikan terhadap kemungkinan financial distress.

Ha3: Agency cost berpengaruh positif signifikan terhadap kemungkinan financial distress.

Ha4: Managerial ownership berpengaruh negatif signifikan terhadap kemungkinan financial 
distress.

Ha5: Institutional ownership berpengaruh negatif signifikan terhadap kemungkinan financial distress.

Ha6: Independent commissioner proportion berpengaruh negatif signifikan terhadap kemungkinan financial distress.

\section{METODOLOGI}

Penelitian ini memfokuskan pada seluruh perusahaan sektor industri manufaktur yang terdaftar di BEI pada tahun 2017-2019. Pemilihan sampel menggunakan non-probability purposive sampling, yang mana perusahaan yang dijadikan sampel penelitian harus memiliki kriteria-kriteria sebagai berikut:

- Perusahaan sektor industri manufaktur yang terdaftar di BEI pada tahun 2017-2019.

- Perusahaan menyampaikan laporan tahunan selama tahun terdaftar tersebut.

- Laporan keuangan menggunakan basis mata uang Rupiah.

- Terdapat data yang dibutuhkan dalam penelitian di dalam laporan tahunan dan keuangan.

Berdasarkan kriteria-kriteria di atas, didapat jumlah data sebanyak 117. Seluruh data diobservasi melalui laporan tahunan dan keuangan yang dipublikasikan di laman BEI dan laman perusahaan. Operasionalisasi variabel ini juga akan dijabarkan di Tabel 1 sebagai berikut:

Tabel 1. Operasionalisasi Variabel-Variabel

\begin{tabular}{|c|c|c|}
\hline Variabel & Pengukuran & Skala \\
\hline $\begin{array}{c}\text { Financial } \\
\text { Distress }\end{array}$ & Z EMS $\geq 4.16:$ :0" & Nominal \\
\hline Zurrent Ratio & $\frac{\text { Current Asset }}{\text { Current Liabilities }}$ & Rasio \\
\hline $\begin{array}{c}\text { Debt to Asset } \\
\text { Ratio }\end{array}$ & TotalDebt & RotalAsset \\
\hline $\begin{array}{c}\text { Agency Cost } \\
\text { Managerial } \\
\text { Ownership }\end{array}$ & Total Shares Held by Directors \& Commissioners \\
\hline $\begin{array}{c}\text { Institutional } \\
\text { Onwership }\end{array}$ & Total Outstanding Shares & Rasio \\
\hline $\begin{array}{c}\text { Independent } \\
\text { Commissioner } \\
\text { Proportion }\end{array}$ & $\frac{\text { Total Shares Held by Institutions }}{\text { Total Outstanding Shares }}$ & Rasio \\
\hline
\end{tabular}

Financial distress diukur dengan Z EMS dan kategorinya tertera di Tabel 2 sebagai berikut: $Z \sim E M S=3.25+6.56 X 1+3.26 X 2+6.72 X 3+1.05 X 4$

X1: Net Working Capital / Total Asset

X2: Retained Earning / Total Asset

X3: Earning Before Interest and Taxes / Total Asset

X4: Book Value Equity / Book Value Debt 
Handoko dan Handoyo: Pengaruh Kinerja Keuangan, Biaya Keagenan, Dan ...

Tabel 2. Tabel Cut-off Z EMS dan Kesetaraan Dengan Bond Rating

\begin{tabular}{|c|c|c|c|}
\hline Zone & Z EMS & Bond Rating & Category \\
\hline Safe Zone & $\geq 5.86$ & AAA - BBB & "0" \\
\hline Grey Zone & $5.85-4.16$ & BBB(-) - B & "0" \\
\hline Distress Zone & $\leq 4.15$ & B(-) - D & "1" \\
\hline
\end{tabular}

Sumber: Terinspirasi oleh Altman (2005), kemudian data diolah, 2020.

Dalam penelitian ini, dilakukan uji statistik deskriptif, uji multikolinearitas, uji regresi logistik, Uji Hosmer and Lemeshow's Goodness of Fit, Uji Likelihood Ratio, Uji McFadden RSquared, dan Expectation Prediction, dengan menggunakan Software E-Views 11.

\section{HASIL ANALISIS DATA}

Uji asumsi multikolinearitas menggambarkan tentang korelasi antar variabel-variabel independen dalam penelitian (Ghozali, 2018:105). Berdasarkan Tabel 3, tidak terdapat korelasi antar variabel-variabel independen yang melebihi 0.80 (Gujarati, 2003:359).

Tabel 3. Tabel Multikolinearitas Correlation

\begin{tabular}{|rrrrrrr|}
\hline & X1_CR & X2_DAR & X3_AGC & X4_MANOWN X5_INSOWN X6_INDCOMP \\
\hline \hline X1 CR & 1.000000 & -0.787570 & -0.098482 & 0.177081 & -0.315319 & 0.079474 \\
X2_DAR & -0.787570 & 1.000000 & 0.147070 & -0.249289 & 0.331498 & -0.035826 \\
X3_AGC & -0.098482 & 0.147070 & 1.000000 & -0.029274 & 0.061190 & -0.081778 \\
X4 MA & 0.177081 & -0.249289 & -0.029274 & 1.000000 & -0.608899 & 0.113079 \\
X5_INS & -0.315319 & 0.331498 & 0.061190 & -0.608899 & 1.000000 & -0.040705 \\
X6_IND & 0.079474 & -0.035826 & -0.081778 & 0.113079 & -0.040705 & 1.000000 \\
\hline
\end{tabular}

Uji statistik deskriptif adalah penggambaran karaktersitik data, yang bertujuan menggambarkan secara detail data kuantitatif sampel (Ghozali, 2018:19). Dari 117 sampel, financial distress mean keseluruhan 0.1196, median 0, maksimum 1, minimum 0, dan standar deviasi 0.3259. Current ratio mean 2.0326 (sehat 2.2234 dan distress 0.6287), median 1.5077, maksimum 5.8666, minimum 0.0857, dan standar deviasi 1.3693. Debt to asset ratio mean 0.4761 (sehat 0.4383 dan distress 0.7543 ), median 0.4713, maksimum 1.2536, minimum 0.1155, dan standar deviasi 0.2082. Agency cost mean 0.0836 (sehat 0.0689 dan distress 0.1922 ), median 0.0608, maksimum 1.5, minimum 0.0077, dan standar deviasi 0.1395. Managerial ownership mean 0.0878 (sehat 0.0903 dan distress 0.0692 ), median 0.0093 , maksimum 0.6828 , minimum $6.11 \mathrm{e}^{-9}$, dan standar deviasi 0.1474. Institutional ownership mean 0.7455 (sehat 0.7467 dan distress 0.7366), median 0.8361, maksimum 0.9903, minimum 0.0005, dan standar deviasi 0.2654. Independent commissioner proportion mean 0.414 (sehat 0.4205 dan distress 0.3666 ), median 0.4 , maksimum 0.8333 , minimum 0.2 , dan standar deviasi 0.1034 .

Uji regresi logistik merupakan model pengujian pengaruh pada variabel independen terhadap variabel dependen, yang mana berskala nominal (Hosmer et al., 2013). Hasil analisis regresi logistik dapat disimpulkan dengan tabel di bawah ini: 
Tabel 4. Uji Regresi Logistik

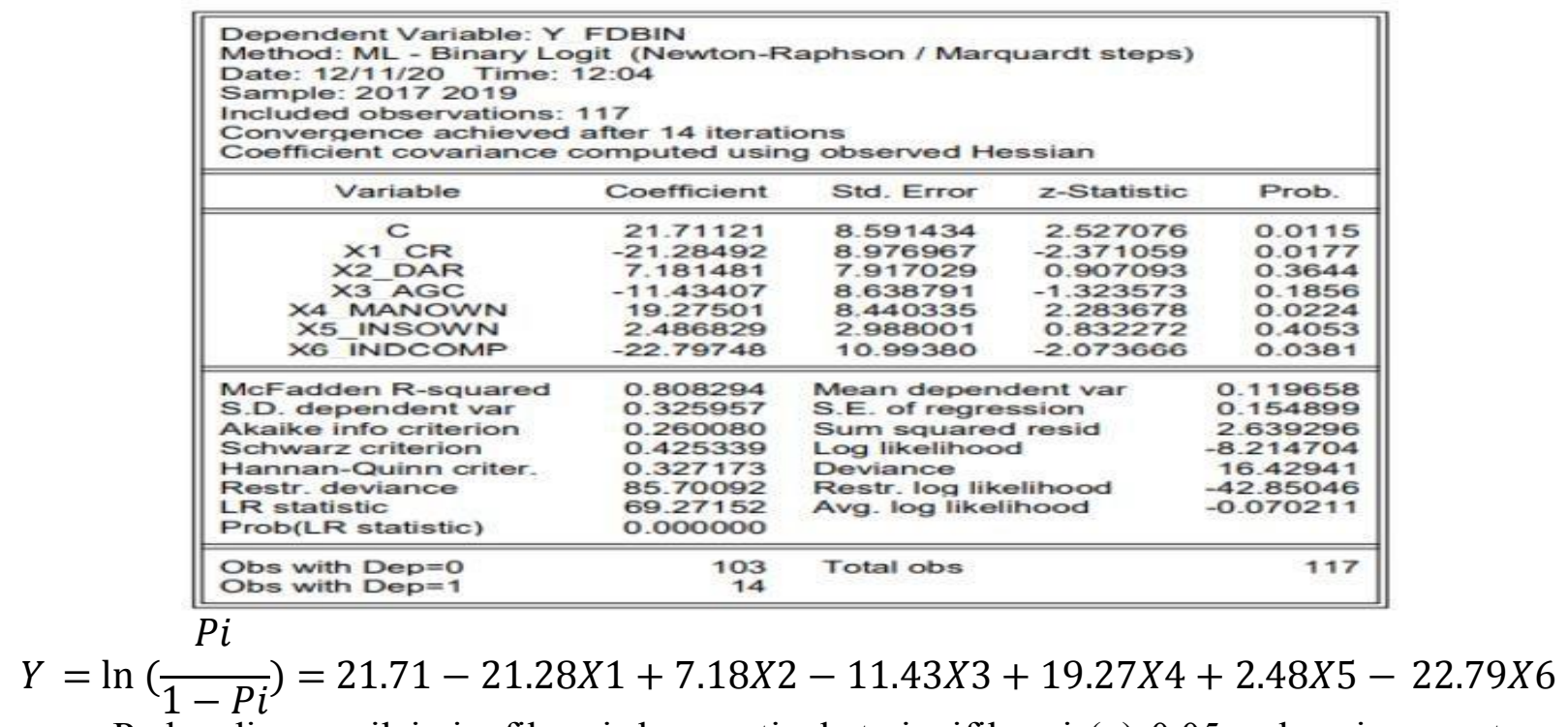

Perbandingan nilai signfikansi dengan tingkat signifikansi $(\alpha) 0.05$, sebagai pernyataan hasil analisis yang signifikan atau tidak, dilihat pada Tabel 4. Current ratio berkoefisien negatif dan signifikan $0.0177 \leq 0.05$. Debt to asset ratio berkoefisien positif dan tidak signifikan 0.3644 $\geq 0.05$. Agency cost berkoefisien negatif dan tidak signifikansi $0.1856 \geq 0.05$. Managerial ownership berkoefisien positif dan signifikansi $0.0224 \leq 0.05$. Institutional ownership berkoefisien positif dan tidak signifikansi $0.4053 \geq 0.05$. Independent commissioner proportion berkoefisien negatif dan signifikansi $0.0381 \leq 0.05$.

Tabel 5. Uji Goodness of Fit

\begin{tabular}{|c|c|c|c|c|c|c|c|c|}
\hline \multicolumn{9}{|c|}{$\begin{array}{l}\text { Goodness-of-Fit Evaluation for Binary Specification } \\
\text { Andrews and Hosmer-Lemeshow Tests } \\
\text { Equation: UNTITLED } \\
\text { Date: } 12 / 11 / 20 \text { Time: } 12: 08 \\
\text { Grouping based upon predicted risk (randomize ties) }\end{array}$} \\
\hline & \multicolumn{2}{|c|}{ Quantile of Risk } & \multicolumn{2}{|c|}{ Dep $=0$} & \multicolumn{2}{|c|}{ Dep $=1$} & \multirow{2}{*}{$\begin{array}{c}\text { Total } \\
\text { Obs }\end{array}$} & \multirow{2}{*}{$\begin{array}{c}\mathrm{H}-\mathrm{L} \\
\text { Value }\end{array}$} \\
\hline & Low & High & Actual & Expect & Actual & Expect & & \\
\hline 1 & 2.E-49 & 2.E-34 & 11 & 11.0000 & 0 & 1.8E-34 & 11 & 1.8E-34 \\
\hline 2 & 2.E-33 & 4.E-25 & 12 & 12.0000 & 0 & $4.2 \mathrm{E}-25$ & 12 & 4.2E-25 \\
\hline 3 & 3.E-24 & 6.E-14 & 12 & 12.0000 & 0 & 8. $9 \mathrm{E}-14$ & 12 & 8.9E-14 \\
\hline 4 & 2.E-13 & 2.E-09 & 11 & 11.0000 & 0 & $2.9 \mathrm{E}-09$ & 11 & 2. $9 \mathrm{E}-09$ \\
\hline 5 & 5.E-09 & 1.E-06 & 12 & 12.0000 & 0 & 4.5E-06 & 12 & 4.5E-06 \\
\hline 6 & 1.E-06 & 0.0003 & 12 & 11.9994 & 0 & 0.00056 & 12 & 0.00056 \\
\hline 7 & 0.0004 & 0.0027 & 11 & 10.9881 & 0 & 0.01188 & 11 & 0.01189 \\
\hline 8 & 0.0041 & 0.0320 & 12 & 11.8227 & o & 0.17732 & 12 & 0.17997 \\
\hline 9 & 0.0557 & 0.6367 & 9 & 9.46466 & 3 & 2.53534 & 12 & 0.10797 \\
\hline \multirow[t]{2}{*}{10} & 0.7445 & 1.0000 & 1 & 0.72510 & 11 & 11.2749 & 12 & 0.11092 \\
\hline & & Total & 103 & 103.000 & 14 & 14.0000 & 117 & 0.41133 \\
\hline \multirow{2}{*}{\multicolumn{3}{|c|}{$\begin{array}{l}\text { H-L Statistic } \\
\text { Andrews Statistic }\end{array}$}} & 0.4113 & & \multirow{2}{*}{\multicolumn{2}{|c|}{$\begin{array}{l}\text { Prob. Chi-Sa(8) } \\
\text { Prob. Chi-Sq(10) }\end{array}$}} & 0.9999 & \\
\hline & & & 33.6507 & & & & 0.0002 & \\
\hline
\end{tabular}

Uji Hosmer and Lemeshow's Goodness of Fit adalah pengujian fit pada model regresi logistik secara keseluruhan (Hosmer et al., 2013). Berdasarkan Tabel 5, nilai Prob Chi-square sebesar $0.99 \geq 0.05$, yang menyatakan model regresi logistik dalam penelitian ini fit dan layak untuk digunakan dalam penelitian.

Uji Likelihood Ratio adalah pengujian untuk menilai pengaruh simultan variabel independen terhadap variabel dependen (Gujarati, 2003:606). Berdasarkan Tabel 4, nilai Prob LR Statistic sebesar $0.00 \leq 0.05$, yang menyatakan current ratio, debt to asset ratio, agency cost, managerial ownership, institutional ownership, dan independent commissioner proportion secara simultan berpengaruh signifikan terhadap kemungkinan financial distress.

Uji McFadden $R$-Squared merupakan nilai yang menandakan kemampuan variabel 
independen menjelaskan variabel dependen (Gujarati, 2003:605). Berdasarkan Tabel 4, nilai McFadden R-Squared $80.82 \%$, menyatakan current ratio, debt to asset ratio, agency cost, managerial ownership, institutional ownership, dan independent commissioner proportion dapat menjelaskan financial distress, dan sisa $19.18 \%$ dijelaskan variabel lain diluar penelitian ini.

Tabel 6. Tabel Expectation Prediction

\begin{tabular}{|c|c|c|c|c|c|c|}
\hline \multicolumn{7}{|c|}{$\begin{array}{l}\text { Expectation-Prediction Evaluation for Binary Specification } \\
\text { Equation: UNTITLED } \\
\text { Date: } 12 / 11 / 20 \text { Time: } 12: 09 \\
\text { Success cutoff: } C=0.5\end{array}$} \\
\hline & \multicolumn{3}{|c|}{ Estimated Equation } & \multicolumn{3}{|c|}{$\begin{array}{l}\text { Constant Probability } \\
\text { Dep }=1\end{array}$} \\
\hline$P(D e p=1)<=C$ & 102 & 2 & 104 & 103 & 14 & 117 \\
\hline & & 12 & & & 0 & o \\
\hline $\begin{array}{l}\text { P(Dep }=1)>C \\
\text { Total }\end{array}$ & 103 & 14 & 117 & 103 & 14 & 117 \\
\hline Correct & 102 & & 114 & 103 & & 103 \\
\hline$\%$ Correct & 99.03 & 85.71 & 97.44 & 100.00 & 0.00 & 88.03 \\
\hline$\%$ Incorrect & 0.97 & 14.29 & 2.56 & 0.00 & 100.00 & 11.97 \\
\hline \multirow[t]{3}{*}{ Percent Gain "- } & -0.97 & $\begin{array}{l}85.71 \\
85.71\end{array}$ & $\begin{array}{r}9.40 \\
78.57\end{array}$ & & & \\
\hline & \multicolumn{3}{|c|}{ Estimated Equation } & \multicolumn{3}{|c|}{ Constant Probability } \\
\hline & Dep $=0$ & Dep $=1$ & Total & Dep $=0$ & Dep $=1$ & Total \\
\hline$E(\#$ of $D e p=0)$ & 100.46 & 2.54 & 103.00 & 90.68 & 12.32 & 103.00 \\
\hline$E(\#$ of $\mathrm{Dep}=1)$ & 2.54 & 11.46 & 14.00 & 12.32 & 1.68 & 14.00 \\
\hline Total & 103.00 & 14.00 & 117.00 & 103.00 & 14.00 & 117.00 \\
\hline Correct & 100.46 & 11.46 & 1117.92 & $\begin{array}{l}103.00 \\
90.68\end{array}$ & 14.68 & 92.35 \\
\hline \% Correct & $\begin{array}{r}100.46 \\
97.53\end{array}$ & 81.84 & 95.65 & 88.03 & 11.97 & 78.93 \\
\hline$\%$ Incorrect & 2.47 & 18.16 & 4.35 & 11.97 & 88.03 & 21.07 \\
\hline Total Gain - & 9.50 & 6988 & 16.72 & & & \\
\hline Percent Gain -- & 79.37 & 79.37 & 79.37 & & & \\
\hline
\end{tabular}

Uji Expectation Predicition merupakan penilaian keakurasian prediksi atas model regresi logistik (Gujarati, 2003). Berdasarkan Tabel 6, persentase akurasi 97.44\% dan kesalahan 2.56\%, dimana model prediksi sangat akurat.

\section{DISKUSI}

Berdasarkan hasil analisis, current ratio berpengaruh negatif signifikan terhadap kemungkinan financial distress. Hasil ini sesuai dengan teori Platt \& Platt (2002) dan Beaver et al. (2010) yang mengindikasikan peningkatan current ratio berpengaruh pada penurunan risiko financial distress, yang mana perusahaan yang likuid akan terhindar dari risiko financial distress, karena perusahaan memiliki sumber daya lancar yang cukup, sehingga Ha1 tidak ditolak. Hasil penelitian ini serupa dengan penelitian Kazemian et al. (2017), Shidiq \& Khairunnisa (2019), dan Sanny \& Warastuti (2020), serta bertentangan dengan penelitian Susilowati et al. (2019) yang menyatakan current ratio tidak berpengaruh terhadap kemungkinan financial distress.

Berdasarkan hasil analisis, debt to asset ratio berpengaruh positif tidak signifikan terhadap kemungkinan financial distress. Hasil ini tidak sesuai dengan teori Platt \& Platt (2002) dan Beaver et al. (2010). Ini mengindikasikan penurunan debt to asset ratio tidak berpengaruh pada penurunan risiko financial distress, yang disebabkan perusahaan sehat maupun distress cenderung memiliki hutang besar, sehingga Ha2 ditolak. Hasil penelitian ini serupa dengan penelitian Erayanti (2019), serta bertentangan dengan penelitian Kazemian et al., (2017), Udin et al. (2017), Susilowati et al. (2019), dan Sanny \& Warastuti (2020) yang menyatakan debt to asset ratio berpengaruh tidak signifikan terhadap kemungkinan financial distress.

Berdasarkan hasil analisis, agency cost berpengaruh negatif tidak signifikan terhadap kemungkinan financial distress. Hasil ini tidak sesuai dengan teori Jensen \& Meckling (1976) dan $\mathrm{Li}$ et al. (2008). Ini mengindikasikan penurunan agency cost tidak berpengaruh pada penurunan risiko financial distress, yang disebabkan jumlah perusahaan distress sedikit dan ratarata agency cost tidak seimbang dibandingkan dengan rata-rata agency cost perusahaan sehat, sehingga Ha3 ditolak. Hasil penelitian ini serupa dengan penelitian Susilowati et al. (2019), serta bertentangan dengan penelitian Li et al. (2008) dan Prastiwi \& Dewi (2019) yang menyatakan 
agency cost berpengaruh positif signifikan terhadap kemungkinan financial distress.

Berdasarkan hasil analisis, managerial ownership berpengaruh positif signifikan terhadap kemungkinan financial distress. Hasil ini tidak sesuai dengan teori Jensen \& Meckling (1976) dan Scott (2003). Ini mengindikasikan penurunan managerial ownership berpengaruh pada penurunan risiko financial distress, yang disebabkan pemegang saham manajerial adalah afiliasi perusahaan yang mungkin mementingkan kepentingan afiliasi, sehingga Ha4 ditolak. Hasil penelitian ini serupa dengan penelitian Udin et al. (2017), serta bertentangan dengan penelitian Manzaneque et al. (2016), Luqman et al. (2018), dan Prastiwi \& Dewi (2019) yang menyatakan managerial ownership berpengaruh negatif signifikan terhadap kemungkinan financial distress.

Berdasarkan hasil analisis, institutional ownership berpengaruh positif tidak signifikan terhadap kemungkinan financial distress. Hasil ini tidak seusai dengan teori Brigham \& Daves (2007), Ahmad \& Septriani (2008), dan Udin et al. (2017). Ini mengindikasikan penurunan institutional ownership tidak berpengaruh pada penurunan risiko financial distress, yang disebabkan jumlah pemegang saham institusi saat perusahaan sehat dan distress sama, serta institusi merupakan entitas induk yang mungkin mengendalikan perusahaan untuk kepentingan entitas induk, sehingga Ha5 ditolak. Hasil penelitian ini serupa dengan penelitian Manzaneque et al. (2016) dan Witiastuti \& Suryandari (2016), serta bertentangan dengan penelitian Udin et al. (2017) dan Prastiwi \& Dewi (2019) yang menyatakan institutional ownership berpengaruh negatif signifikan terhadap kemungkinan financial distress.

Berdasarkan hasil analisis, independent commissioner proportion berpengaruh negatif signifikan terhadap kemungkinan financial distress. Hasil ini sesuai dengan teori Scott (2003), Krisnauli \& Hadiprajitno (2014), dan Luqman et al. (2018), yang mengindikasikan peningkatan jumlah komisaris independen berpengaruh pada penurunan risiko financial distress, yang mana perusahaan dengan komisaris independen yang banyak akan terhindari dari risiko financial distress karena mekanisme pengawasan akan lebih baik, sehingga Ha6 tidak ditolak. Hasil penelitian ini serupa dengan penelitian Li et al. (2008), Manzaneque et al. (2016), dan Nursiva \& Widyaningsih (2020), serta bertentangan dengan penelitian Witiastuti \& Suryandari (2016) dan Sanny \& Warastuti (2020) yang menyatakan independent commissioner proportion berpengaruh tidak signifikan terhadap kemungkinan financial distress.

\section{PENUTUP}

Berdasarkan hasil pengujian data dalam penelitian ini, maka dapat disimpulkan bahwa: current ratio berpengaruh negatif terhadap kemungkinan financial distress. Debt to asset ratio tidak berpengaruh terhadap kemungkinan financial distress. Agency cost tidak berpengaruh terhadap kemungkinan financial distress. Managerial ownership berpengaruh positif terhadap kemungkinan financial distress. Institutional ownership tidak berpengaruh terhadap kemungkinan financial distress. Independent commissioner proportion berpengaruh negatif terhadap kemungkinan financial distress.

Penelitian ini masih terdapat keterbatasan seperti variabel, waktu penelitian yang singkat, dan sampel perusahaan manufaktur. Beberapa saran yang dapat disampaikan sebagai berikut. Bagi peneliti berikutnya perlu memperluas rentang waktu penelitian untuk mendapat data lebih banyak, agar didapat data-data yang bervariasi, dan memberikan karakteristik data, yang dapat menjelaskan pengaruh solvabilitas, biaya keagenan, dan kepemilikan institusional terhadap kemungkinan financial distress. Bagi perusahaan dan agen perlu menjaga tingkat likuiditas tinggi dan pengawasan komisaris independen yang baik agar perusahaan tidak mengalami kondisi financial distress. Bagi investor perlu menjadikan tingkat likuiditas dan pengawasan komisaris independen sebagai indikator penilaian kelayakan investasi pada agar tidak berinvestasi pada perusahaan distress. 


\section{DAFTAR PUSTAKA}

Ahmad, A. W., \& Septriani, Y. (2008). Konflik Keagenan: Tinjauan Teoritis dan Cara Menguranginya. Jurnal Akuntansi Dan Manajemen, 3(2), 47-55.

Ahrendsen, B. L., \& Katchova, A. L. (2012). Financial ratio analysis using ARMS data. Agricultural Finance Review, 262-272. https://doi.org/10.1108/00021461211250492

Altman, E. I. (2005). An Emerging Market Credit Scoring System For Corporate Bonds.

Emerging Market Review, 6, 311-323.

Beaver W. H., M. C. and M. F. M. (2010). Financial Statement Analysis and the Prediction of Financial Distress, Foundation and Trends in Accounting. Foundation and Trends in Accounting, 5(2), 99-173.

Brigham, E. F., \& Daves, P. R. (2007). Intermediate Financial Management (9th Edition). https://doi.org/10.1016/0890-8389(89)90100-5

Dwijayanti, S. (2010). Penyebab, Dampak, Dan Pbediksi Dari Financial Distress Serta Solusi Untuk Mengatasi Financial Distress. Jurnal Akuntansi Kontemporer, 2(2), 191-205.

Eisenhardt, K. M. (1989). Agency Theory: An Assessment and Review. Academy of Management Review, 14(1), 57-74. https://doi.org/10.1159/000169659

Erayanti, R. (2019). Pengaruh Likuiditas, Profitabilitas dan Leverage terhadap Prediksi Financial Distress. Jurnal Riset Akuntansi \& Perpajakan (JRAP), 6(01), 38-51.

Ghozali, Imam. (2018). Aplikasi Analisis Multivariate dengan Program IBM SPSS 25.

Semarang: Universitas Diponegoro

Gujarati, D. N. (2003). Basic Econometrics Fourth Edition (4th Editio). United States Military Academy, West Point.

Hosmer, D. W. J., Lemeshow, S., \& Sturdivant, R. X. (2013). Applied Logistic Regression. In John Wiley \& Sons (3rd Editio). John Wiley \& Sons, Inc. https://doi.org/10.2307/2348743

Jensen, M. C., \& Meckling, W. H. (1976). Theory Of The Firm : Managerial Behavior, Agency Costs And Ownership Structure. Journal of Financi, 3, 305-360.

Katadata.

(2020).

(Retrivied

from:

https://katadata.co.id/happyfajrian/finansial/5e9a4c3ba18f4/jadi-tumpuan-ekonomi-ri-

sektor-manufaktur-2019-tumbuh-melambat 15-01-2021)

Kazemian, S., Shauri, N. A. A., Sanusi, Z. M., Kamaluddin, A., \& Shuhidan, S. M. (2017). Monitoring mechanisms and financial distress of public listed companies in Malaysia. Journal of International Studies, 10(1), 92-109. https://doi.org/10.14254/20718330.2017/10-1/6

Kementerian BUMN. (2002). Keputusan Menteri BUMN No. KEP-117/M-MBU/2002

(Retrivied from: http://jdih.bumn.go.id/lihat/KEP-117/M-MBU/2002. 27-10-2020)

Lesmana. (2003). Pedoman Menilai Kinerja Untuk Perusahaan Tbk, Yayasan, BUMN, BUMD, dan Organisasi Lainnya, Edisi Pertama, Jakarta: Elex Media Komputindo

Li, H. X., Wang, Z. J., \& Deng, X. L. (2008). Ownership, independent directors, agency costs and financial distress: Evidence from Chinese listed companies. Corporate Governance, 8(5), 622-636. https://doi.org/10.1108/14720700810913287

Lizal, L. (2002). Determinants of Financial Distress: What Drives Bankruptcy in a Transition Economy? The Czech Republic Case. SSRN Electronic Journal, 451.

Luqman, R., Ul hassan, M., Tabasum, S., Khakwani, M. S., \& Irshad, S. (2018). Probability of financial distress and proposed adoption of corporate governance structures: Evidence from Pakistan. Cogent Business and Management, 5(1), 1-14. 
https://doi.org/10.1080/23311975.2018.1492869

Manzaneque, M., Priego, A. M., \& Merino, E. (2016). Corporate Governance Effect on Financial Distress Likelihood: Evidence From Spain. Revista de Contabilidad-Spanish Accounting Review, 19(1), 111-121. https://doi.org/10.1016/j.rcsar.2015.04.001

Matar, A., \& Eneizan, B. M. (2018). Determinants of Financial Performance in the Industrial Firms: Evidence from Jordan. Asian Journal of Agricultural Extension, Economics \& Sociology, 22(1), 1-10. https://doi.org/10.9734/ajaees/2018/37476

Nursiva, K., \& Widyaningsih, A. (2020). Financial Distress In Indonesia: Viewed From Governance Structure. Jurnal Riset Akuntansi Dan Keuangan, 8(2), 205-220. https://doi.org/10.17509/jrak.v8i2.27796

Platt, H. D., \& Platt, M. B. (2002). Predicting corporate financial distress: Reflections on choicebased sample bias. Journal of Economics and Finance, 26(2), 184-199. https://doi.org/10.1007/bf02755985

Prastiwi, B. I., \& Dewi, R. (2019). Pengaruh Managerial Agency Cost Terhadap Financial Distress Dengan Struktur Kepemilikan Sebagai Variabel Pemoderasi. Jurnal Informasi, Perpajakan, Akuntansi, Dan Keuangan Publik, 14(1), 81.

https://doi.org/10.25105/jipak.v14i1.5016

Sanny, \& Warastuti, Y. (2020). Analisis Pengaruh Kinerja Keuangan danTata Kelola Perusahaan Terhadap Kondisi Kesehatan Keuangan Perusahaan. Jurnal Akuntansi Bisnis, 18(1).

Scott, W. R. (2003). Financial Accounting Theory (3rd ed.). Toronto, Ontario: Pearson Education Canada Inc.

Shidiq, J. I., \& Khairunnisa. (2019). Analisis Rasio Likuiditas, Rasio Leverage, Rasio Aktivitas, dan Rasio Pertumbuhan Terhadap Financial Distress Menggunakan Metode Altman ZScore Pada Sub Sektor Tekstil dan Garmen di BEI Periode 2013-2017. Financial Management, 17-48.

Shleifer, A., \& Vishny, R. W. (1997). A Survey of Corporate Governance Andrei. The Journal of Finance, 1(2), 737-783.

Susilowati, Y., Suwarti, T., Puspitasari, E., \& Nurmaliani, F. A. (2019). The Effect of Liquidity, Leverage, Profitability, Operating Capacity, and Managerial Agency Cost on Financial Distress of Manufacturing Companies Listed in Indonesian Stock Exchange. Advances in Economics, Business and Management Research, 100, 651-656. https://doi.org/10.2991/icoi-19.2019.114

Udin, S., Khan, M. A., \& Javid, A. Y. (2017). The effects of ownership structure on likelihood of financial distress: an empirical evidence. Corporate Governance (Bingley), 17(4), 589612. https://doi.org/10.1108/CG-03-2016-0067

Witiastuti, R. S., \& Suryandari, D. (2016). The Influence of Good Corporate Governance (GCG) on Financial Distress. Review of Integrative Business and Economics Reseacrh, 5(1), 118 127. https://doi.org/10.2991/insyma-18.2018.19 